\title{
Hora de analizar la evidencia de izquierda a derecha
}

\author{
It is time to analyze the evidence from left to right
}

Waldo H Belloso $o^{a, b, c}$

\begin{abstract}
Resumen
En este artículo, el autor reflexiona sobre las expectativas de los profesionales de la salud acerca de la evidencia para recomendar tratamiento farmacológico a los pacientes con COVID-19.

\section{Abstract}

In this article, the author reflects on the expectations of health professionals regarding the evidence to recommend pharmacological treatment to patients with COVID-19.
\end{abstract}

Palabras clave: Infecciones por Coronavirus, Medicina Basada en la Evidencia. Keywords: Coronavirus Infections, Evidence-Based Medicine.

Belloso WH. Hora de analizar la evidencia de izquierda a derecha. Evid Actual Pract Ambul. 2020;23(2):e002053.

¿Con qué tratar a los pacientes que hoy presentan una neumonía por Covid-19? ¿Con qué argumentos combatir la desesperación de la gente que sale a las farmacias a aprovisionarse de hidroxicloroquina? Las recomendaciones de tratamientos que hoy se hacen desde varios rincones: ¿cuánto contribuyen al camino del conocimiento y cuánto se sustentan en nuestra ansiedad terapéutica?

"Las verdades en medicina son falacias transitoriamente irrefutables" decía el gran Paco Maglio. Y claramente es así, todo nuestro conocimiento es contingente. Aunque una aspiración científica honesta es que algunas de estas contingencias resulten lo suficientemente persistentes como para sustentar paradigmas. $\mathrm{Y}$, siguiendo a Kuhn, es así como la ciencia progresa ${ }^{1}$.

Estas inusuales épocas de pandemia ofrecen el caldo de cultivo ideal para la destrucción de muchos paradigmas. Sociales y científicos. Y la contingencia necesaria para que las seudoverdades que creemos tener se evaporen aún más velozmente que lo que tardamos en aprenderlas.

En medicina nos acostumbramos a mirar los riesgos relativos de factores predisponentes de enfermedades y de nuestras propias intervenciones. Aunque en la vida cotidiana los seres humanos no nos guiamos por riesgos relativos. Analizamos (o intuimos) los riesgos absolutos. Frente a una enfermedad que se propaga con tanta rapidez, las comparaciones de riesgos y de tasas con otras patologías aparentemente similares nos desvían la atención del número absoluto que debe ocuparnos: cuántas personas enfermarán gravemente y cuántas morirán en este lapso. La propia evolución de la pandemia y su llegada más tardía a nuestro escenario nos permiten analizar su dinámica intrínseca. Ya cuando este episodio se supere, nos sentaremos a comparar tasas en nuestras presentaciones en congresos.

No existen dudas que el problema es serio, y que un gran número de personas van a requerir de nuestra dedicación y de nuestra inteligencia. Hoy la necesidad nos obliga a buscar lo antes posible tratamientos efectivos.

Y lógicamente no tenemos tiempo para pensar en desarrollar uno o más fármacos específicos contra los blancos de acción más adecuados del SARS-CoV-2. Sin embargo el remanido paradigma del embudo o la pirámide acostada para graficar el desarrollo de los fármacos aún es válido en estas circunstancias. Aquí no serán "candidatos" diseñados por ingeniería los que larguen la carrera sino el conjunto de moléculas que tenemos disponibles y a los que, por distintas razones, les asignamos cierta potencialidad. Casi como ir al garaje de autopartes o a la caja de herramientas, y ver qué tenemos por allí que nos pudiera servir.

Pero para definir qué nos puede ser de utilidad, lo primero que debemos considerar es qué esperamos encontrar. El hecho que se trate de un "enemigo invisible" no implica que sea desconocido. Sabemos mucho del virus, conocemos su secuencia genética, su ciclo vital y cuáles son los potenciales sitios de acción farmacológica (o los más evidentes, al menos). Ya el historiador Frank Snowden planteó que esta es la primera gran epidemia de la globalización ${ }^{2}$. Tenemos a la mano una gran cantidad de recursos informativos disponibles. No poder verlo no significa estar a ciegas.

De hecho, los infectólogos dedicamos toda nuestra vida a conocer y trabajar con organismos que no podemos ver a simple vista.

Al igual que siempre, aquí el punto crítico se basa en hacerse las preguntas correctas. Tanto para recomendar pautas provisorias de tratamiento como así también para el diseño de los estudios clínicos más informativos.

¿Cuál es la chance que todas las observaciones de efecto de los distintos tratamientos que hoy pueblan las páginas de las revistas sean solamente producto del azar? ¿O simplemente representen el fenómeno de regresión a la media? ¿Cuál es el n mínimo necesario para definir una señal clara por encima del ruido para cada uno de los desenlaces más pertinentes? $O$ al revés, ¿cuál debería ser el tamaño del efecto de una intervención para encontrar indicios convincentes en estudios de 30,50 o 100 participantes?

¿Cuál es la plausibilidad biológica de que la azitromicina reduzca efectivamente la carga viral del coronavirus?

¿Por qué identificamos a lopinavir/ritonavir como el pilar principal del tratamiento? ¿Cuán inesperado fue que el único ensayo clínico controlado con este fármaco haya tenido resultado negativo? ¿Ese resultado dependió solamente de problemas del diseño del estudio? ¿Acaso la concentración intracelular inhibitoria del fármaco para SARS-CoV-2 no sea tan sencilla de alcanzar in vivo? Aún más: ¿es la inhibición de la proteasa el mecanismo más vulnerable del virus sobre el que podemos actuar? Y en todo caso, ¿cuál sería la utilidad potencial del resto de los inhibidores de proteasa con que hoy contamos?

Los Coronavirinae se caracterizan por presentar un genoma de ARN inusualmente grande, dos tercios del cual codifica a la replicasa (ARN polimerasa ARN dependiente). ¿Podría ser este

\footnotetext{
a Servicio de Clínica Médica, Hospital Italiano de Buenos Aires.

b Departamento de Investigación, Hospital Italiano de Buenos Aires.

c Departamento de Farmacología y Toxicología, Instituto Universitario Hospital Italiano de Buenos Aires. waldo.belloso@hospitalitaliano.org.ar
} 
un blanco de acción más eficaz que otros? Y si así fuera, ¿con qué alternativas al remdesivir contamos? ¿Por qué se puso mayor atención inicialmente a la inhibición de la proteasa con antirretrovirales que a la inhibición potencial de la replicasa por la ribavirina?

¿Existe algún indicio de evidencia sobre la conveniencia de dar tratamiento combinado? ¿Sabemos cuáles combinaciones son sinérgicas? ¿O cuando menos aditivas? $Y$ en caso que querer establecer un tratamiento combinado, ¿no sería más lógico sumar fármacos que actúen sobre blancos secuenciales?

¿Importan los estudios clínicos de drogas candidatas en otras enfermedades aparentemente relacionadas? Sí, claro que importan. Nos dan información sobre todo acerca de la tolerancia y seguridad de los fármacos en poblaciones con características similares. Pero ¿son predictivos de eficacia clínica? No necesariamente. Al menos no más que lo que se parezcan las historias naturales de esas dos enfermedades.

Los que intentamos hacer lectura crítica de la evidencia médica nos acostumbramos a mirar los datos empezando por el extremo derecho. Establecemos unos parámetros de búsqueda, filtramos todo lo que no se adecue, y nos detenemos sólo en lo mínimo que no hemos descartado. $Y$ analizamos las fortalezas y los potenciales sesgos para sacar conclusiones. La crítica a la evidencia es un gran ejercicio del pensamiento científico para momentos de sosiego. Hoy ya sabemos de antemano que la mayor parte de lo que se publique será de baja calidad. Este es el momento para generar evidencia. De sembrar el terreno con las preguntas correctas para que lo que aparezca cuente con un poco más de oportunidades de sobrevivir a la primera crítica.

Las decisiones políticas son para los políticos. Nuestra tarea es proveerles sustento e información, en especial en estos momentos en que hay gran receptividad. Y participar de las estrategias de comunicación no sólo es deseable sino imprescindible. Pero puertas adentro no podemos perder nuestra capacidad crítica sobre nuestros actos, debemos cuestionar permanentemente las efímeras verdades que sostienen nuestro castillo de naipes para estar dispuestos a armar uno nuevo cada día, ligeramente más sólido.

Lógicamente, estamos en un escenario incómodo. Por necesidades y urgencias. Pero esa incomodidad nunca nos debe llevar a condicionar las preguntas a las falacias transitoriamente irrefutables que hoy tenemos. Y que seguramente mañana ya no estarán más.

Definamos cuáles son las preguntas más relevantes que debemos hacernos para que la evidencia tímida que recibamos o que generemos pueda empezar de a poco a llenar los vacíos en la dirección correcta. Es hora de mirar la evidencia terapéutica de izquierda a derecha.

\section{Referencias}

1. Kuhn TS. La estructura de las revoluciones científicas. Fondo de Cultura Económica de España; 2005.

2. Alconada-Mon H. Frank Snowden: Las epidemias son como mirarse al espejo de la humanidad, y puedo decir que no todo es bello; 2020 . Available from: https://www.lanacion.com.ar/el-mundo/frank-snowden-las-epidemias-son-como-mirarse-al-espejo-de-la-humanidad-y-puedo-decir-queno-todo-es-bello-nid2348455 [Last access: 2020-04-08]. 